\title{
Pozzolanic Activity of Fly Ash
}

\author{
K. N. Farooque ${ }^{a *}$, Z. Yeasmin ${ }^{a}$, S. Alam ${ }^{b}$, A. M. S. Alam ${ }^{b}$ and M. Zaman ${ }^{a}$ \\ ${ }^{a}$ IGCRT, BCSIR, Dhanmondi, Dhaka ${ }^{b}$ Department of Chemistry, Dhaka University, Dhaka, Bangladesh
}

\begin{abstract}
Various physico-chemical properties such as particle size distribution, specific gravity, specific surface area, chemical composition, solubility of Fly Ash (FA) in $\mathrm{NaOH}$ and pozzolanic activity of fly ash towards lime have been investigated. Chemical analysis of FA reveals that the FA used in this present investigation belongs to class F type of fly ash. XRD investigation of FA depicts the presence of crystalline mullite and quartz phases. Pozzolanic activity of fly ash was investigated by $\mathrm{pH}$ and electrical conductivity measurement, by determining the amount of calcium reacted with fly ash and by the amount of Insoluble Residue (IR) observed in FA-lime paste. XRD investigation of ash-lime paste identified the Calcium Silicate Hydrate (C-S-H) phase. The results obtained from these studies suggested that fly ash possesses pozzolanic activity.
\end{abstract}

Key words: Pozzolanic activity, Fly ash (FA), Rice husk ash, Ordinary Portland Cement (OPC), Insoluble residue (IR), Calcium hydroxide (CH), Calcium silicate hydrate (C-S-H), Kinetics, XRD.

\section{Introduction}

FA has been in use throughout the world for more than 60 years for making variety of building materials. The ash is the residue generated from the combustion of solid pulverized fuel (coal) in big thermoelectric power plants. This ash is most widely used in artificial pozzolana in USA as well as in many other countries (McMillan and Powers, 1934 ; Paya et al., 1995). Davis et al., 1937 indicates that FA is a source of pozzolana. Pozzolana is a material which itself may possess little or no cementitious value but in presence of moisture, reacts with $\mathrm{Ca}(\mathrm{OH})_{2}$ to form cementitious compounds. FA reacts with lime to produce C-S-H (calcium silicate hydrate), which is responsible for development of strength in brick or block produced by utilizing FA (Chen et al., 2000). These bricks/blocks are suitable for use in masonry instead of common burnt clay brick at lower cost. The interaction of FA and $\mathrm{CH}$ has attracted the attention of several researchers and extensive study was carried out on fly ash-lime reaction (Huang Cheng, 1986; Kumar, 2003; Basumajumdar et al., 2005). Joseph et al., 2001 studied the kinetics of reaction between $\mathrm{FA}$ and $\mathrm{Ca}(\mathrm{OH})_{2}$ at temperature $25-60^{\circ} \mathrm{C}$ by using Thermo Gravimetric Analysis (TGA). Huge quantity of unused industrial wastes FA is generated in Barapukoria Power Plant which can be reused by combing with lime in the building industries. Lime can also be made available either from mineral sources or may be collected from paper mill/fertilizer industries as lime sludge. The reactivity or the availability of FA to combine with lime depends on the type of FA as the composition of FA varies depending on the type of coal (Vassilev and Vassileva, 2005). About 316/188 minerals or mineral-groups have been identified in coals and FA's respectively. The chemistry of the reaction between FA and lime is not well understood and needs further investigation. Therefore an attempt has been made to study the reactivity of FA towards lime.

\section{Materials and Methods}

\section{a) Materials}

1. Fly ash- FA was collected from Meghna Cement Factory.

2. Lime: Lime, for making LA-lime paste was collected from local market.

3. Analytical grade reagents were used to carry out this study and they were purchased from MERCK.

\section{b) Methods}

1. The particle size distribution was carried out by ASTM C 618 (sieve specification: ASTM, E 11 - 70).

\footnotetext{
* Corresponding author: E-mail: ysom2002@yahoo.com
} 
2. The specific gravity and specific surface area was determined by ASTM C 204 - 00 and ASTM C 188 - 95 respectively.

3. Chemical analysis- Chemical analysis involves fusion of FA with $\mathrm{Na}_{2} \mathrm{CO}_{3}$ and subsequent analysis by gravimetric method (ASTM). Iron oxide was determined by UVspectrophotometer. Lime was analyzed adopting the same method.

4. Solubility of FA in $\mathrm{NaOH}$ - The test was carried out by taking fine powder sample (325- mesh) of FA and 0.5M $\mathrm{NaOH}$ solution. $1.0 \mathrm{~g}$ of FA was taken and $\mathrm{NaOH}$ solution was added. The solution was boiled for 10 minutes and filtered through Whatman-42 filter paper. The residue was washed with distilled water. It was then ignited in a previously weighed platinum crucible. From the difference in the weight of the crucible, solubility of the ash sample in $\mathrm{NaOH}$ was determined.

5. Electrical conductivity and $\mathrm{pH}$ measurements $-50 \mathrm{ml}$ saturated (11.4 mmolar) $\mathrm{Ca}(\mathrm{OH})_{2}$ solution (solution temperature $28^{\circ} \mathrm{C} \pm 1$ ) was taken in a beaker. $0.0912 \mathrm{~g}$ FA was added to the solution under constant stirring. A digital $\mathrm{pH}$ meter and an electrical conductivity were used to record the variations in $\mathrm{pH}$ value and electrical conductivity of the solution with time. The results are shown in Fig. 1.

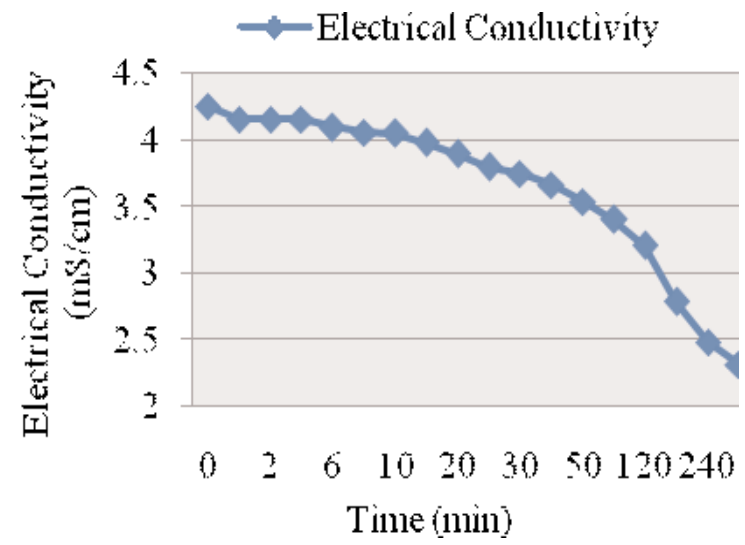

carbon dioxide. After 7 days the mixture was filtered into a $250 \mathrm{~mL}$ volumetric flask and the solution was diluted up to the mark. Then the unreacted calcium ion was determined by titration against standard $0.01 \mathrm{M}$ EDTA with solochrome Black-T as indicator. Each titration was carried out five times and the results were taken from the reproducible data. A blank was run before each experiment. Similar method was followed for pre-determined times ranging 14 to 90 days. From the unreacted calcium ion the percent of calcium that reacted with FA was calculated. The Fig. 2 showed the percent reactivity of FA with lime.

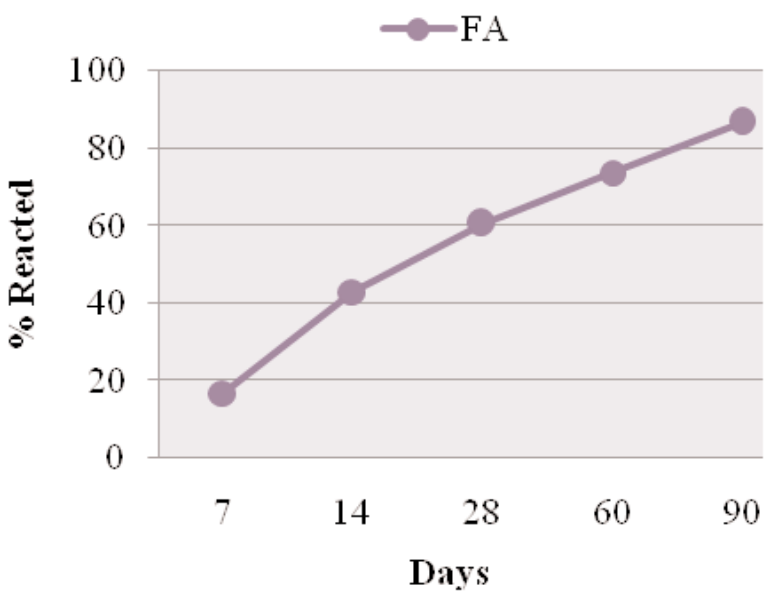

Fig 2: Kinetics of FA-Lime reaction

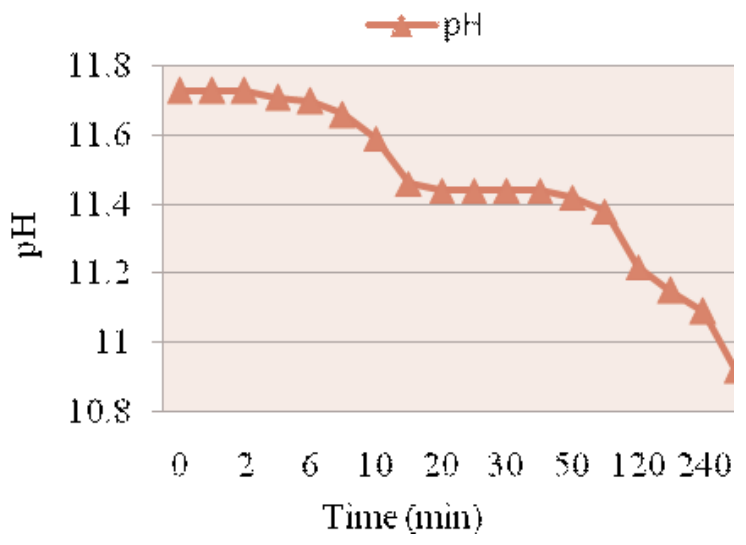

Fig 1: Conductivity and pH measurements

6. Kinetics of FA-Lime - The reactivity FA towards lime was determined as follows. 0.0912g of FA was weighed out into five $100 \mathrm{~mL}$ conical flask. $50 \mathrm{~mL}$ of saturated lime (11.4mmolar) solution was added into each conical flask and the flasks were preserved in desiccator covered with aluminum foil to avoid contact with atmospheric
7. The insoluble residue content was determined according to Vogel.

8. X-ray diffractometer (XRD) Model-X'Pert- PW3040/60, Philips using $\mathrm{CuK} \alpha$ radiation with Ni filter was used for determination of phases present in fine powder of FA and FA-lime paste. Paste sample was prepared by mix- 
ing FA and lime at 1:1 ratio and cured for 90 days. All samples were tested using $40 \mathrm{kV}(30 \mathrm{~mA})$ at step size 0.02 degree/s and $2 \theta$ values ranging from 5.01 to 90.00 degrees. Intensity and $d$-values were compared with the values available in the data book of "Selected Powder Diffraction Data for Minerals".

\section{Results and Discussion}

The particle size distribution showed that $50 \%$ of particles are lower than $0.045 \mathrm{~mm}$ and $48 \%$ particles are above than $0.045 \mathrm{~mm}$ (Table I). This value showed disagreement with ASTM C 618 [maximum sieve residue is $32 \%$ on $45 \mu \mathrm{m}$ ]. The result indicates that FA used in present investigation did not match with ASTM 618 specification as far as particle size is concerned.

Table I: Particle size distribution

\begin{tabular}{c|c}
\hline Size & FA (\%) \\
\hline $0.15(100+$ mesh) & 6.43 \\
$0.075(200+$ mesh) & 20.97 \\
$0.045(325+$ mesh $)$ & 21.25 \\
(325- mesh) & 49.28 \\
\hline
\end{tabular}

The specific gravity of FA was found to be 2.13. This value is within the range for pulverized FA that is 1.9-2.4 (Oyetola and Abdullahi, 2006). However, the value is less than the cement which is 3.15 .

The specific surface area was found to be $183.14 \mathrm{~m}^{2} / \mathrm{kg}$, is less than that of cement. According to ASTM C 618 the minimum specific surface (Blaine) for FA is $325 \mathrm{~m}^{2} / \mathrm{kg}$.

Chemical analysis mainly has been focused on the major and minor oxides present in FA. According to ASTM C 618 the sum of $\mathrm{SiO}_{2}+\mathrm{Al}_{2} \mathrm{O}_{3}+\mathrm{Fe}_{2} \mathrm{O}_{3}$ in FA should be $70 \%$ for the application of pozzolana cements, concrete, lime/cement based bricks/blocks and maximum sulfur content is $5 \%$. The maximum loss on ignition is $12 \%$. From the analysis of FA (Table II) it is evident that all the values are within the range. Hence the experimental FA was categorized as Class F type of FA. Analysis of lime indicated that it contains higher percentage of $\mathrm{CaO}(98.37 \%)$.

Results on solubility showed that FA contains $10.41 \%$ insoluble matter. The solubility of ash sample indicates the degree of crystallinity as well as reactivity (Yeoh et al., 1979). XRD results (Fig. 3) reveals that FA contains more crystalline phases like crystalline quartz and mullite. However, silica
Table II: Chemical composition of FA and lime

\begin{tabular}{c|c|c}
\hline $\begin{array}{c}\text { Name of the } \\
\text { compounds }\end{array}$ & $\begin{array}{c}\text { FA } \\
\text { wt. (\%) }\end{array}$ & $\begin{array}{c}\text { Lime } \\
\text { wt. (\%) }\end{array}$ \\
\hline $\begin{array}{c}\text { Loss on Ignition } \\
\mathrm{SiO}_{2}\end{array}$ & $\begin{array}{c}2.36 \\
61.07\end{array}$ \\
& & - \\
$\mathrm{Fe}_{2} \mathrm{O}_{3}$ & 02.60 & 0.35 \\
$\mathrm{Al}_{2} \mathrm{O}_{3}$ & 27.43 & 0.10 \\
$\mathrm{CaO}$ & 03.83 & 98.37 \\
$\mathrm{MgO}^{\mathrm{SO}}$ & 02.12 & 01.45 \\
\hline
\end{tabular}

and alumina are in fact less vulnerable to calcium hydroxide when the compound is crystalline. As FA contains more crystalline phases the solubility of FA in $\mathrm{NaOH}$ is less.

The $\mathrm{pH}$ and electrical conductivity of saturated $\mathrm{CH}$ solution at $27.9^{\circ} \mathrm{C}$ were 11.7 and $4.26 \mathrm{mS} / \mathrm{cm}$ respectively (Fig. 1). After adding $\mathrm{FA}$, the $\mathrm{pH}$ values remain unchanged up to 6 min and gradually decreases (Heikal et al., 2004) with time until 15 min. Then again $\mathrm{pH}$ value remained constant until 50 min (11.42). Afterwards there is a drop in $\mathrm{pH}$ (10.92) after $300 \mathrm{~min}$. It is evident from this experimental result that both $\mathrm{Ca}^{2+}$ and $\mathrm{OH}$ - concentration of the solution were reduced with time though very slowly, because $\mathrm{pH}$ is directly related to the amount of free $\mathrm{OH}^{-}$anions in the solution. The decrease in the $\mathrm{pH}$ value can be attributed to the interaction between FA and $\mathrm{CH}$. The electrical conductivity of $\mathrm{CH}$ saturated solution at 0 min was 4.26. As FA was added the electrical conductivity started decreasing very slowly, as FA takes time to react with $\mathrm{CH}$ at room temperature. The electrical conductivity reached $2.32 \mathrm{mS} / \mathrm{cm}$ after 300min. Hence, both the electrical conductivity and $\mathrm{pH}$ test results indicate the interaction between FA and $\mathrm{CH}$.

The reaction between FA and saturated lime solution were performed by determining the percent of $\mathrm{CH}$ reacted through EDTA titration (Fig. 2). Both $\mathrm{CH}$ and FA were consumed as the reaction progress. At the initial period the reaction is slow as revealed by the percent of calcium reacted (16.66\%). This is because of the chemical composition of FA which belongs to the $\mathrm{CaO}-\mathrm{SiO}_{2}-\mathrm{Al}_{2} \mathrm{O}_{3}$ system, contains less $\mathrm{CaO}$ compared to silica and alumina (Huang and Cheng, 1986). The ability of FA to react with lime mainly depends in the breaking of its glass phase (Fraay et al. 1989). After 14, 28, 60 and 90 days gradually the percent of $\mathrm{CaO}$ reacted was increased. This increase is may be due to the breakdown of the densified outer layer of FA particle leaving more 


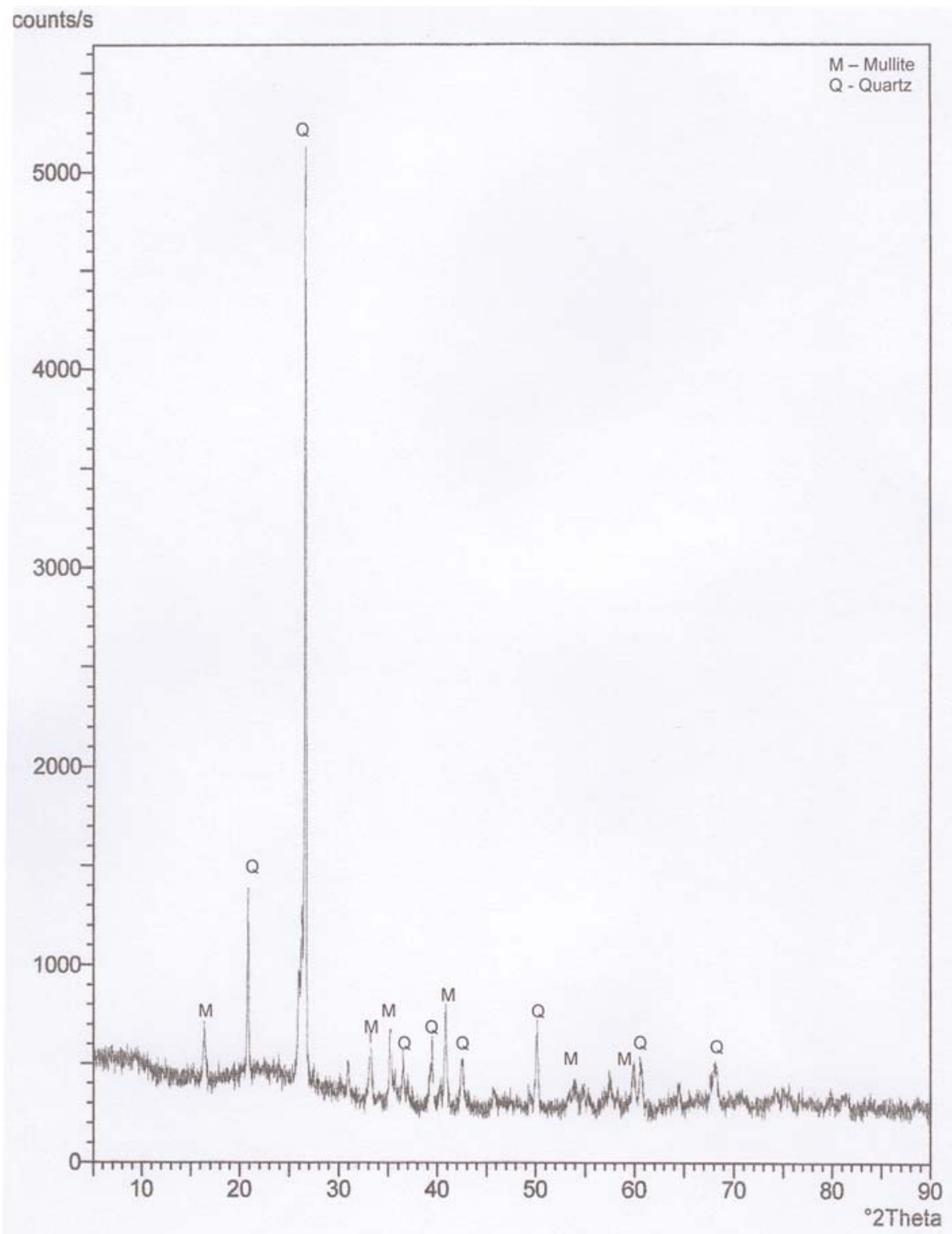

Fig 3: XRD of FA

active sites exposed for $\mathrm{CaO}$ to react which takes some time (Shi, 1999).

Insoluble residue (IR) of FA-lime paste was illustrated in Table III. It is known that a pozzolana is not soluble in $\mathrm{HCl}$ solution; on the other hand silica originating from lime silica

Table III: Insoluble residue of Ash-Lime composite cements

\begin{tabular}{c|c}
\hline Age (days) & FA-Lime (1:1) (wt \%) \\
\hline 1 & 67.44 \\
28 & 43.22 \\
60 & 30.00 \\
\hline
\end{tabular}

reaction producing $\mathrm{C}-\mathrm{S}-\mathrm{H}$ is soluble in $\mathrm{HCl}$. Therefore increase in soluble silica and decrease in insoluble residue of the Ash-lime composite cement is an indication of pozzolanic reactivity. Gradual decrease in IR content may be due to the dissolve of glass phase present in the firm network of silicate or aluminate, in the basic pore solution (Hanehara et al., 2001).

XRD Observation - Fig. 3 and 4 show the X-ray diffractogram of FA and FA-Lime paste (1:1) respectively. From the diffractogram of FA it is clear that it contains crystalline quartz and mullite (Chen et al., 2000). Only the major phases 


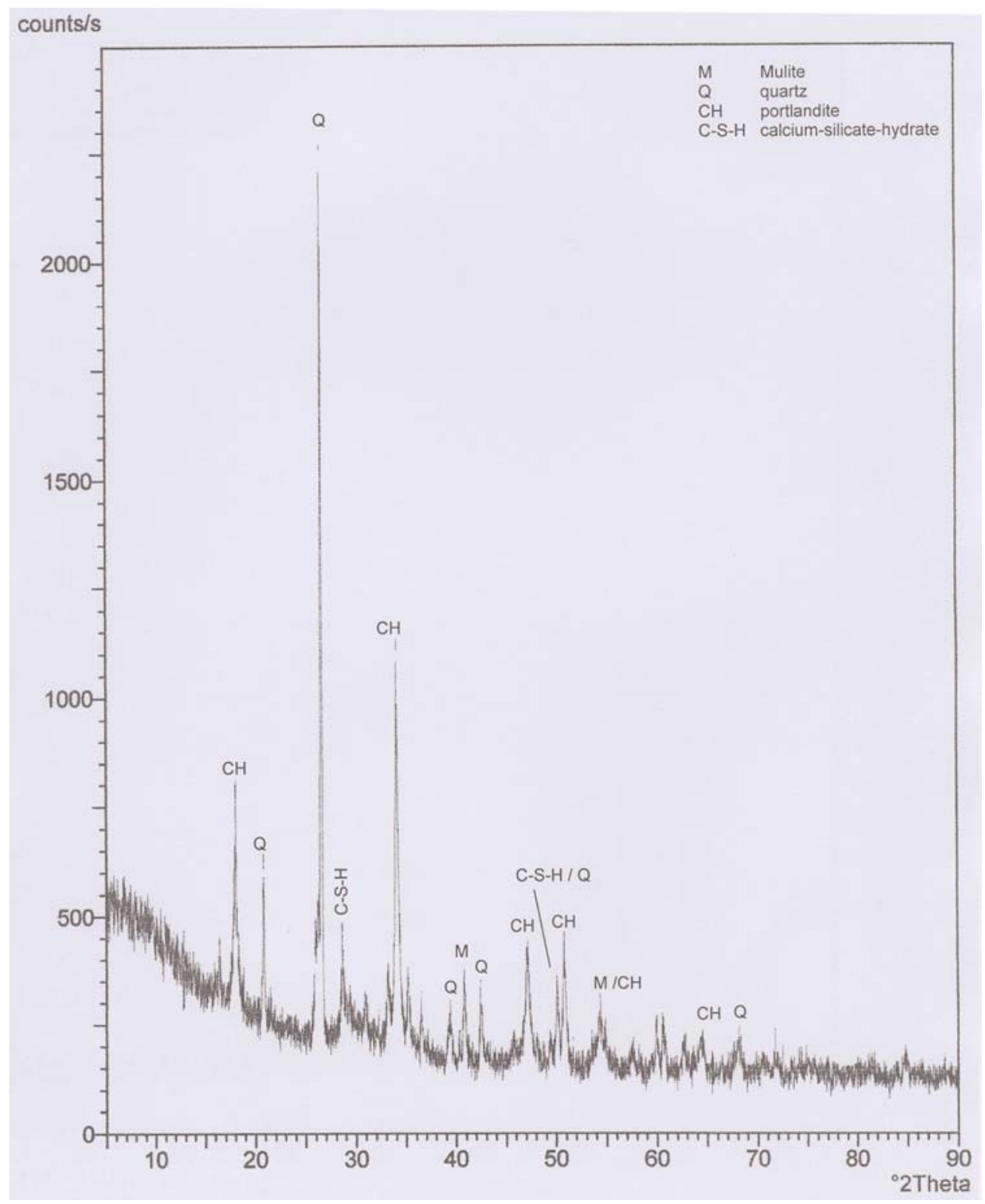

Fig 4: XRD of 90 days old FA:Lime (1:1) paste

are illustrated in the Fig. 3. The main phases identified in the paste sample comprise quartz, mullite, portlandite (calcium hydroxide, $\mathrm{CH}$ ), C-S-H (calcium silicate hydrate). When the diffractogram of fly ash-lime paste was compared with the FA, five major new peaks appeared at angle $2 \theta$ (18.07, 29.37, 34.12, 47.11, 50.81) with corresponding $d$-spacing (4.904, 3.037, 2.625, 1.889 and 1.795) $\AA$. Among them, peak at $2 \theta 29.37$ is responsible for C-S-H phase (Chen et al., 2004 and Qijun Yu et al., 1990) and rest of the peaks indicating $\mathrm{CH}$ phase. Peak at $2 \theta 50.14$ ( $d$-spacing of $1.817 \AA$ ) could be assigned for C-S-H /quartz. As the peak-intensity of C-S-H is very low it might be possible to overlap with the sharp- quartz peak. However, it is not possible to determine the actual structure of C-S-H by XRD that was formed during hydration. Because all forms of C-S-H that are sufficiently crystalline give peaks in these region, they are not diagnostic to determine the structure (Chen et al., 2004). So, there is the conclusive evidence for the formation of $\mathrm{C}-\mathrm{S}-\mathrm{H}$ in the setting of fly ash-lime paste.

\section{Conclusion}

From the present investigation it appeared that

* The experimental FA was class F type FA in terms of its chemical composition. 
* About $10.41 \%$ of FA is insoluble in $\mathrm{NaOH}$.

* Decrease in $\mathrm{pH}$ and conductivity indicates free $\mathrm{OH}$ reacted slowly with silica and alumina present in fly ash.

* The kinetics study indicated that initially pozzolanic reaction between FA and $\mathrm{Ca}(\mathrm{OH})_{2}$ proceeded slowly and later on at an appreciable rate.

* Decrease in insoluble residue indicates the FA-lime reaction proceeds with time and formation of C-S-H phase.

* XRD of FA-lime paste identified C-S-H phase which is the main binding component of the pozzolanic cement.

\section{References}

Basumajumdar A., Das A. K., Bandyopadhyay N. and Maitra S. (2005). Some studies on the reaction between fly ash and lime. Bull. Mater. Sci., 28 (2): 131-136.

Chen J. J., Thomas J. J., Taylor H. F. W. and Jennings H. M. (2004). Solubility and structure of calcium silicate hydrate. Cement and Concrete Research, 34: 14991519.

Chen Li D., Shen Y., Su J. and Wu J. X. (2000). The influence of alkalinity on activation and microstructure of fly ash, Cem.Concr. Res., 30: 881-886.

Davis R. E., Carlson R. W., Kelly J. W. and Davis H. E. (1937). Properties of Cements and Concretes containing fly ash.. Proceedings American Concrete Institute, 33: 577-612.

Fraay A. L. A., Bijen J. M and deHaan Y. M. (1989). The reaction of fly ash in concrete, a critical examination, Cem. Concr. Res., 19 (2): 235-246.

Hanehara S., Tomosawa F., Kobayakawa M. and Hwang K. Y. (2001). Effects of water/powder ratio, mixing ratio of fly ash and curing temperature on pozzolanic reaction of fly ash in cement paste. Cem. Concr. Res., 31: 31-39

Heikal M., Helmy I., El-Didamony H. and El-Raoof F. A. (2004). Electrical properties, physico-chemical and mechanical characteristics of fly ash-limestone filled pozzolan Fic cement. Ceramic- Silikaty, 48 (2): 49-58.

Huang S. and Cheng J. (1986). Kinetic of reaction in the system fly ash-Ca(OH) $)_{2}-\mathrm{H}_{2} \mathrm{O}$. J. Chin. Ceram. Soc., 14 (1): 191-197.
Joseph J., Biernacki P., Williams J. and Stutzman P. E. (2001). Kinetics of reaction of calcium hydroxide and fly ash. ACI Materials Journal, 98 (4): 340-349.

Kumar S. (2003). Fly ash-lime-phosphogypsum hollow blocks for walls and partitions. Building and Environment, 38: 291-295.

Lea F. M. (1938). The Pozzolana Proceedings: Symposium Chemistry of Cement, Stockholm, 460-490.

McMillan F. R. and Powers T. C. (1934). A Method of Evaluating Admixtures. Proceedings Am. Concr. Inst., 30: $325-344$.

Malquori G. (1960). Portland-Pozzolana Cement. 4th Int. Symposium, Washington, Vol. 11: 983-1006.

Massazza F. (1998) Pozzolana and Pozzolanic Cements, in Lea's Chemistry of Cement and Concrete, Hewlett P.C. ed., 4th Ed. (Arnold Publ., London): 471-631.

Oyetola E. B. and Abdullahi M. (2006). The use of rice husk ash in low - cost sandcrete block production. Leonardo Electronic Journal of Practices and Technologies, 8: 58-70.

Paya J., Monzo J., Borchero M. V. and Peris-Mora E. (1995). Mechanical Treatment of fly ashes Part 1 : PhysicoChemical Characterization of Ground Fly Ashes. Cem. Concr. Res., 25: 1469-1479.

Shi C. (1999). Studies on several factors affecting hydration and properties of lime-pozzolan cements. J. Mater. Civ. Eng., 29 (4): 467-472.

Vogel A. I. (1962). A text book of quantitative inorganic analysis including instrumental analysis, 3rd Ed. (ELBS): 663-664.

Vassilev S. V. and Vassileva C. G. (2005). Methods for characterization of composition of fly ashes from coal-fired power stations: A critical overview. Energy \& Fuels, 19: $1084-1098$.

Yeoh A. K., Bidin R., Chong C. N. and Tay C. Y. (1979). The relationship between temperature and duration of rice husk in the development of amorphous rice husk ash silica, UNIDO/RCTT follow up meeting on Rice Husk Cement, Alor Setar, Malaysia.

Received : June 11, 2009;

Accepted : January 26, 2010 